\title{
Deteksi Koksidiosis pada Ayam Layer di Desa Sesaot, Kecamatan Narmada, Kabupaten Lombok Barat
}

\author{
Detection of Coccidiosis in Layer Chicken in Sesaot, Narmada District \\ West Lombok
}

\author{
Dian Yusnia Fitri1 ${ }^{*}$, Alfiana Laili Dwi Agustin ${ }^{(\mathbb{D}}{ }^{,}$Kholik $^{2}{ }^{(\mathbb{D}}$, Maratun Janah $^{3}$ \\ 1Mahasiswa Pendidikan Dokter Hewan, \\ 2Divisi Kesehatan Masyarakat Veteriner, \\ 2Divisi Mikrobiologi dan Parasitologi, \\ Fakultas Kedokteran Hewan, Universitas Pendidikan Mandalika \\ J1. Pemuda No. 59A, Dasan Agung Baru, Mataram \\ Telp/Fax : (0370) 632082 \\ *E-mail : dianyusniafitri160@gmail.com
}

\begin{abstract}
ABSTRAK
Koksidiosis merupakan penyakit yang di sebabkan oleh protozoa spesies Eimeria sp. yang dapat menginfeksi ayam. Eimeria sp. adalah spesies yang paling patogen dan menyebabkan diare berdarah pada ayam. Satu kendala yang dirasakan oleh peternak di sana adalah adanya penyakit berak darah pada ayam layer di Desa Sesaot kecamatan Narmada Lombok Barat. Tujuan penelitian untuk mengetahui adanya endoparasit koksidiosis pada ayam layer yang dipelihara di Sesaot kecamatan Narmada Lombok Barat sebagai langkah untuk melakukan pengendalian terhadap koksidiosis. Sejumlah 9 sampel diambil dari ayam yang menunjukkan gejala klinis terinfeksi koksidia, yaitu diare berdarah. Sampel feses diambil secara aseptis, kemudian dibawa ke Laboratorium Equine Clinical Skills Centre Universitas Pendidikan Mandalika. Sampel yang sudah ada di laboratoirum diperiksa menggunakan metode Pengapungan. Berdasarkan hasil pemeriksaan, terdapat satu sampel positif terinfeksi Eimeria sp. dari total 9 sampel yang diidentifikasi.
\end{abstract}

Kata Kunci: Koksidia,Eimeria sp., Ayam Petelur

\begin{abstract}
Coccidiosis is a disease caused by the protozoan species Eimeria $s p$ which can attack chickens. Eimeria sp. is the most pathogenic species and causes bloody diarrhea in chickens. The aim of this study was to determine the presence of coccidiosis parasite eggs in layer chickens raised in Sesaot, Narmada district, West Lombok. A total of 9 samples was taken from chickens that showed clinical symptoms of coccidia infection,


Fitri et al. MKH (2021). 97-104

DOI: 10.20473/mkh.v32i3.2021.97-104

namely bloody diarrhea. Samples were taken aseptically, then taken to the Laboratory of Equine Clinical Skills Center, Mandalika University of Education. Existing samples in the laboratory were examined using the Flotation method. The results of the examination of 9 samples of chickens examined found that 1 sample was positively infected by Eimeria sp.

Keyword: Coccidia, Eimeria sp., Laying Chickens

\section{PENDAHULUAN}

Penyakit Eimeria sp. ini dapat menyebabkan gangguan terutama pada saluran pencernaan, dengan angka kesakitan dan kematian mencapai $80 \%$, faktor-faktor yang mempengaruhi kejadian Eimeria sp. yaitu jumlah sel induk semang yang rusak, besarnya dosis infeksi ookista, patogenitas galur koksidia, umur, gizi serta penyakit lainnya (Levine, 1985). Masyarakat di Sesaot Lombok Barat merupakan peternak yang mensuplai produk peternakanannya ke wilayah Lombok Barat dan Kota Mataram. Berdasarkan hasil wawancara dengan peternak ayam layer, salah satu kendala yang dirasakan oleh peternak di sana adalah adanya penyakit berak darah pada ayam layer fase starter, jika sudah terdapat ayam yang berak darah maka akan mudah menginfeksi ayam lain yang ada di kandang tersebut. Menurut Kementerian Pertanian (2014), berak darah merupakan salah satu gejala klinis dari penyakit koksidia.

Berdasarkan hasil penelitian Agustin dan Ningtyas (2020), prevalensi kasus koksidiosis di Lombok barat sebesar 52,5\%. Prevalensi yang cukup tinggi tersebut terjadi karena Indonesia memiliki iklim tropis dengan tingkat kelembaban yang cukup tinggi, sehingga mendukung perkembangan parasit ini (Iskandar, 2005). Prevalensi kasus koksidiosis di Indonesia cukup beragam, di Sleman sebesar $16 \%$ di Bandar Lampung sebesar 20\%, di Jimbaran Bali sebesar 43,8\%, di Tabanan Bali sebesar 31,1\% (Halidazia, 2015; Yulian, 2017; Simamora et al. 2017; Arsyitahlia et al., 2019). Penelitian yang dilakukan di Ethiopia oleh Amar et al., (2012), melaporkan bahwa prevalensi Eimeria tenella diperoleh sebesar 37,86 $\%$. Prevalensi Eimeria tenella yang dilaporkan oleh Shiferaw (2014) di negara yang sama, yakni sebesar 60,27\% pada unggas lokal. Prevalensi Eimeria tenella yang lebih tinggi juga dilaporkan oleh Gyorke et al.(2013) di Romania dan Haug et al.(2008) di Norwegia pada ayam, yakni sebesar $61 \%$ dan 77\% (Simamora et al, 2017).

Koksidiosis dapat menyebabkan kerugian yang besar pada peternakan unggas akibat terhambatnya pertumbuhan, penurunan bobot badan dan kualitas karkas, penurunan produksi telur dan kematian (Tabbu, 2002; Kharismawan, 2006; Michels et al., 
Fitri et al. MKH (2021). 97-104

DOI: 10.20473/mkh.v32i3.2021.97-104

2001). Pemberantasan dengan menggunakan koksidiostat di laporkan belum optimal, bahkan telah terjadi resistensi bila digunakan dengan tidak tepat sehingga menimbulkan residu obat pada daging dan telur (Doviansyah et al., 2015). Selain itu, rendahnya pengetahuan peternak dalam pengendalian koksidiosis juga berkontribusi dalam meningkatnya potensi resistensi Eimeria sp. terhadap koksidiostat (Ekawasti dan Martindah, 2019).

\section{MATERI DAN METODE}

Jenis penelitian ini adalah penelitian deskriptif yang bertujuan untuk mendeteksi Koksidiosis dalam populasi, dengan rancangan penelitian menggunakan metode survei, survei dilakukan pada kandang yang melaporkan adanya kejadian berak darah pada ternaknya dengan pendekatan cross sectional study. Pengambilan sampel dilakukan secara purposive, yaitu pengambilan sampel dengan kriteria tertentu, sampel yang akan diambil dari ayam yang menunjukan gejala lemas dan masih banyak ayam yang mengeluarkan feses yang disertai dengan perdarahan dari kandang peternak mandiri di Sesaot, Kecamatan Narmada, Lombok Barat dengan populasi sebesar 1.200. Jumlah sampel ditentukan dengan metode detect disease to estimate proportion untuk menetukan proporsi positif dalam suatu populasi, maka jumlah sampel yang di gunakan pada penelitian ini yaitu 9 sampel feses dihitung dengan menggunakan rumus Martin (1987).

$$
\text { n: } 1-(1-C L)^{\frac{1}{D}}\left(N-\frac{\mathrm{D}-1}{2}\right)
$$

Keterangan:

$\mathrm{n}$ : Jumlahsampel yang diperlukan

CL : Confidence Level

DJ : Jumlah yang akan diperkirakan negatif/positif dalam sampel

$\mathrm{N}$ : Populasi

Sampel dalam penelitian ini ditentukan dengan jumlah populasi 1.200, maka perhitungan sampel dengan confidence level (CL) 95\% dan $\mathrm{D}=44,5 \%$ (Simamora et al., 2017). Alat yang digunakan dalam penelitian ini adalah kertas label, mikroskop, gelas ukur, beaker glass, kamera untuk dokumentasi foto, masker, sarung tangan, alat tulis, stopwatch, timbangan analitik untuk menimbang sampel feses yang akan digunakan. Kertas minyak sebagai wadah sampel, yang akan di timbang, saringan 200 mesh untuk menyaring sampel, batang pengaduk, mortar, pipet tetes, spatula dan tisu.

Penelitian ini dilakukan dengan metode apung yaitu feses ayam ditimbang sebanyak 2 gram, ditambahkan air sampai $3 / 4$ tabung dan diaduk sampai homogen, disentrifuge dengan kecepatan 1.500 RPM dalam waktu 5 menit. Tabung sentrifuge dikeluarkan dari dalam sentrifugator, supernatannya dibuang dengan cara dituangkan. Langkah selanjutnya, ditambahkan larutan pengapung $\mathrm{NaCl}$ 
jenuh sampai $3 / 4$ tabung, diaduk sampai homogen. Kemudian disentrifuge kembali dengan kecepatan 1.500 RPM dalam waktu 5 menit. Tabung sentrifuge kemudian dikeluarkan secara hati-hati dari sentrifugator dan selanjutnya ditaruh pada rak tabung reaksi dengan posisi tegak lurus. Cairan pengapung kemudian ditambahkan secara perlahan-lahan dengan cara meneteskannya menggunakan pipet Pasteur sampai permukaan cairan cembung, dengan catatan penambahan cairan pengapung tidak boleh sampai tumpah. Tunggu selama 1-2 menit untuk memberikan kesempatan ookista

\section{HASIL DAN PEMBAHASAN}

Hasil pemeriksaan terhadap 9 sampel ayam yang diperiksa ditemukan mengapung ke permukaan. Gelas penutup diambil, kemudian disentuhkan pada permukaan cairan pengapung dan setelah itu ditempelkan di atas objek gelas. Pemeriksaan dilakukan dengan mikroskop olympus pembesaran obyektif 40X dan diidentifikasi berdasarkan morfologi (bentuk) dan morfometri (ukuran) ookista Eimeria yang diukur dengan optilab (Sufi et al., 2016).

Tabel 1. Hasil pemeriksaan sampel ayam di Desa Sesaot, Kecamatan Narmada, Kabupaten Lombok Barat

\begin{tabular}{ccc}
\hline No. & Hasil Pemeriksaan & Jumlah \\
\hline 1 & Positif & 1 \\
2 & Negatif & 8 \\
\hline
\end{tabular}


Gambar 1. Ookista Eimeriasp yang di temukanpada sampel feses dengan perbesaran 400X dengan ukuran $23 \mu \mathrm{m} \times 18,19 \mu \mathrm{m}$. 
Hasil identifikasi sampel feses menunjukan adanya ookista Eimeria sp. Dengan bentuk terlihatnya empat sporokista pada masing-masing sporozoit pada ayam layer di Sesaot karena kondisi kandang ayam yang kotor. Kondisi kandang ayam yang kotor ini dikarenakan kandang tempat pengambilan sampel penelitian menyatu dengan litter (kotoran) sehingga hal ini memungkinkan Eimeria tersebut dari satu individu menginfeksi individu lainnya ketika feses ayam yang mengandung kista Eimeria sp. yang infektif jatuh pada pakan ayam sehingga ketika ada ayam lain yang makan, feses tersebut dapat tertelan. Hal lain yang menyebabkan ditemukan Eimeria tersebut adalah kandang tempat pengambilan sampel memiliki kondisi kandang yang lembab. Kondisi tempat yang lembab ini sangat mendukung perkembangbiakkan dari Eimeria sp. Menurut Dawid et al., (2012) faktor yang menyebabkan didapatkan Eimeria sp. dalam suatu peternakan adalah kondisi kandang dan manajemen kandang, nutrisi dan sanitasi yang rendah, ras, iklim, kondisi geografis dan keberadaan ookista di lingkungan.

Hasil deteksi Eimeria sp.dari 9 sampel feses yang diperiksa, didapatkan sebesar 11, 11\% (1/9) sampel positif Eimeria sp. Hasil pemeriksan terhadap Eimeria sp. bervariasi tergantung jenis Eimeria dan faktor pendukung kejadian penyakit tersebut. Penelitian tentang prevalensi mencatat bahwa prevalensi jenis $E$.
Tenella di Lampung tahun 2018 mempunyai nilai sebesar $45 \%$, E. Brunetti sebesar 29\%, Eimeria tenella bersporulasi $20 \%$, E. nikamae $12 \%$, dan E. mitis memiliki prevalensi sebesar 10\% (Rosa et al., 2019). Variasi hasil tersebut disebabkan oleh perbedaan tingkat patogenitas dari jenis Eimeria. Cheng (1961) dan Rosa et al (2019) menyatakan prevalensi jenis Eimeria disebabkan karena tingkat patogenisitas dari Eimeria.

Kondisi kandang untuk pengambilan sampel gelap, dan cukup lembab. Keadaan tersebut mendukung perkembangan koksidia didukung dengan kondisi iklim tropis. Menurut Kouwen hoven et al. (1988) kelembaban kandang 80 - 90\%, suhu kandang $28^{\circ}$-C - $29^{\circ} \mathrm{C}$, dan oksigen yang cukup akan mendukung terjadinya sporulasi, proses sporulasi pada ternak ayam disebabkan oleh cahaya, kapasitas kandang per meter luasan, manajemen kandang dan iklim. Apabila kondisi kandang gelap atau kurang cahaya, akan dapat mempercepat proses sporulasi ookista yang akan menyebabkan ookista menjadi infektif dengan iklim. Deteksi Eimeria sp pada Ayam layer yang rendah pada penelitian ini dapat disebabkan karena ayam sudah diberikan koksidiostat tiga hari sebelum diambil sampel sehingga saat pemeriksaan feses tidak ditemukan eimeria pada fesesnya, tetapi feses ayam masih banyak yang berwarna merah darah. 
Fitri et al. MKH (2021). 97-104

DOI: 10.20473/mkh.v32i3.2021.97-104

\section{KESIMPULAN}

Berdasarkan hasil penelitan dari 9 sampel feses didapatkan bahwa Eimeria sp. telah terdeteksi sebesar $11,11 \%(1 / 9)$ pada ayam layer yang telah diberi koksidiostat.

\section{UCAPAN TERIMAKASIH}

Terimakasih kepada peternak mandiri di Sesaot, Kecamatan Narmada, Lombok Barat dan kepada Laboratorium Clinical Skill Center yang telah memberikan izin penelitian dan membantu memfasilitasi saat dilakukan penelitian.

\section{DAFTAR PUSTAKA}

Agustin, A.L.D dan N.S.I. Ningtyas. 2020. PrevelensiKoksidiosis pada ayam broiler di Kecamatan Narmada.

JurnalSangkareangMataram, 6(2), 1-3.

Amar, A., A. Mengistu dan S. Nazir. 2012. Prevalence and Aetiology of Poultry Coccidiosis and Associated Risk Factors in White Leghorn Grower Chickens at Kombolcha Poultry Farm, Ethiopia. Journal of World's Poultry Research 2(3): 54-59.

Arsyitahlia N., I.B.K. Ardana dan I.A.P. Apsari.2019. Prevalensi Infeksi Eimeria spp. PadaAyam Pedaging yang Diberi Pakan Antibiotik Growth Promoters (AGP) di Kabupaten Tabanan,
Bali. Indonesia Medicus

Veterinus. 8(2): 186-192.

Cheng, T.C. 1961. The Biology of Animal Parasites. W.B. Saunders Company. Limited Tokyo, Japan. Page 120-123.

Dawid, F., Y. Ameede, and M. Bekele. 2012. Calf coccidiosis in selected dairy farms of dairy farms of Dire Dawe, Eastern Ethiopia. Global Veterinaria. 9(4): 460-464.

Doviansyah, Z., U. Cahyaningsih dan A. B. Nugraha. 2015. Prevalensi Koksidiosis dan Identifikasi Ookista eimeria Spp. Pada Sapi Perah di Kawasan Usaha Peternakan (Kunak) Kabupaten Bogor. Animal Disease and Veterinary Health. Vol 1:03 787792.

Ekawasti. F. dan E. Martindah. 2019. Pengendalian Koksidiosis Pada Ayam Melalui Pengobatan Herbal (Control of coccidiosis in chickens through herbal medicine). WARTAZOA, 29(1), 001-012 .

Györke. A., L. Pop, and V. Cozma. 2013. Prevalence and distribution " of Eimeria species in broiler chicken farms of different capacities. Parasite 20: 50. doi:10.1051/ parasite/2013052.

Halidazia. 2015. Identifikasi Protozoa Endoparasit Pada Ayam Negeri (Gallus gallus domesticus) di Peternakan Desa Sardonoharjo, Ngalik, Sleman. Skripsi. Universitas Islam Negeri Sunan Kalijaga: Yogyakarta 23-25.

Iskandar, T. 2005. Pengaruh pemberian vitamin A terhadap nilai perlukaan sekum waktu sporulasi dan produksi oosista 
eimeria tenella pada ayam arab. Prosiding Seminar Nasional Teknologi Peternakan dan Veteriner 2005, Pusat Penelitian dan Pengembangan Peternakan. Page 12-19.

Kementerian Pertanian.2014. Manual Penyakit Unggas cetakan ke-2. Jakarta: KementerianPertanian.

Kharismawan, P. 2006. Pengaruh pemberian ekstrak sambiloto (Andrographis paniculata Ness) dengan pelarut metanol terhadap jumlah skizon, mikrogamet, makrogamet dan oosista Eimeria tenella pada sekum ayam [skripsi]. [Bogor (Indonesia)]. Institut Pertanian Bogor.

Kouwenhoven, B.,M. Vertommen and E. Goren. 1988. Investigations into the role of reovirus in the malabsorption syndrome. Avian Pathol. 17: 879-892.

Levine, N. D. 1985. Veterinary Protozology. Ames :Lowa State University Press.

Martin, S.W., A.H. Meek and P. Willeberg. 1987. Veterinary Epidemiology. USA: Iowa State University Press.

Michels, M.G., L.C.T. Bertolini, A.F. Esteves, P. Moreira andS.C. Franca. 2011. Anticoccidial effects of coumestans from Eclipta alba for sustainable control of Eimeria tenella parasitosis in poultry production. Vet Parasitol. 177: 55-60.
Rosa, E., E.N. Yuliana dan E.P. Santoso. 2019. Prevalence of Emelia Genera Upon Coccidiocis Infection Toward Male layer. Jurnal Ilmiah Biologi Eksperimen dan Keanekaragaman Hayati. 6(1), 39-44.

Shiferaw, S. 2014. Study on Prevalence of Poultry Coccidiosis in and Around Ambo, West Shewa Zone, Oromia Regional State, Ethiopia. \{Thesis\}. Ethiopia: Addis Ababa University.

Simamora, S.,P.A.I. Apsari dan M.I. Dwinata. $2017 \quad$ Prevalensi Protozoa Eimeria tenella pada Ayam Buras di Wilayah Bukit Jimbaran, Badung. Indonesia Medicus Veterinus. 6(3). 254261.

Sufi, M.I., U. Cahyaningsih., E. Sudarnika. 2016. Prevalensi dan Faktor Resiko Koksidiosis pada Sapi Perah di Kabupaten Bandung. Jurnal Kedokteran Hewan. 10(2): 195-199.

Tabbu, C.R. 2002. Penyakit Ayam dan Penanggulannya. Yogyakarta (ID) : Kanisisius : 9-12.

Yulian, N. E. 2017. Study Infeksi Koksidia pada Ayam Petelur (Gallus gallus) Strain Lohman Jantan di Peternakan Mandiri Kelurahan Segalamider, Kecamatan Tanjung Karang Barat, Kota Bandar Lampung. \{Skripsi\}. Fakultas Matematika 
Fitri et al. MKH (2021). 97-104

DOI: 10.20473/mkh.v32i3.2021.97-104

dan Ilmu Pengetahuan Alam.

Universitas Lampung. 23-25. 